\title{
Um século de experiência no controle da ancilostomíase
}

\author{
One century of experience in the control of ancylostomiasis
}

\section{Luís Rey}

\begin{abstract}
Resumo A ancilostomíase despertou a atenção do mundo, no começo do século XX, como grave problema de saúde pública e deu origem aos primeiros planos sistemáticos de controle de uma endemia em larga escala. Passou depois a ser vista como questão de menor importância quando surgiram medicamentos antihelmínticos eficazes e o desenvolvimento econômico dos países mais ricos reduziu neles a subnutrição, melhorando ao mesmo tempo as condições habitacionais e sanitárias que tornaram as infecções residuais clinicamente assintomáticas. O problema persiste; entretanto, no terceiro mundo que deve encará-lo com realismo e agir em conseqüência. Sugestôes são feitas nesse sentido.
\end{abstract}

Palavras-chaves: Ancilostomíase. Ancylostoma. Necator. Anemia. Tratamento e controle.

Abstract In the beginning of the XX century, ancylostomiasis was considered a serious public health problem and governments started the first systematic planning for the control of an endemic disease, in large scale. Thereafter, ancylostomiasis was considered a less important subject, because efficient anti-helminthic drugs were introduced, this in combination with the economic development in rich countries, reduced undernourishment and improved housing and sanitary conditions. Consequently, the residual cases of the infection became in general asymptomatic. However, in the third world the problem is still present, and must be considered with realism and managed accordingly. Various suggestions for controling the disease are presented in this paper. Key-words: Ancylostomiasis. Ancylostoma. Necator. Anemia. Treatment and control.

Os ancilostomídeos são helmintos que ou foram herdados pela espécie humana através da evolução simultânea do parasito e do hospedeiro, ou adaptaramse aos homens ou aos nossos ancestrais hominídios, quando esses abandonaram as florestas para viverem em savanas, margens de rios ou lagos e começaram a freqüentar ambientes favoráveis ao ciclo de transmissão dos helmintos de outras espécies ${ }^{2}$. Ainda hoje, podemos nos infectar com os parasitos de canídeos e felídeos, como Ancylostoma ceylanicum e A. caninum.

Mas os homens nômades das épocas pré-históricas, não deviam apresentar infecções importantes ou escapavam completamente do parasitismo quando seus deslocamentos os levavam a regiões com clima ou terreno desfavorável à sobrevivência das larvas do parasito no solo.

Tornando-se sedentários e com residência fixa, crescendo em número e vivendo cada vez mais em coletividades densas, os homens civilizados criaram, por vezes, ecossistemas muito propícios aos helmintos; poluindo intensamente o solo sobre o qual marchavam descalços, eles reuniram condições ótimas para as infecções pesadas e, por conseguinte, para o desenvolvimento da ancilostomíase doença.

Procurou-se em alguns antigos documentos egípcios e gregos referências a um conhecimento sobre esse problema médico que devia existir há mais de dois ou três mil anos. Mas, as interpretações desses textos tendo permanecido sempre muito discutíveis, devemos aceitar como primeira referência clara a esse conhecimento, os escritos de Avicena, famoso médico árabe do século XI, onde ele fala de pequenos vermes redondos que provocam uma forma de anemia ${ }^{618}$. Podemos reconhecer aí os ancilóstomas.

\section{REDESCOBERTA DA ANCILOSTOMÍASE}

Caídos no esquecimento, esses parasitos tiveram que esperar mais alguns séculos para que fossem redescobertos várias vezes e em diferentes países ${ }^{6}$.

Desde 1637, no Brasil, Piso, médico holandês que acompanhava o príncipe Maurício de Nassau, assinala epidemias de uma doença caracterizada por perturbações intestinais, fraqueza e uma anemia que conduzia, por vezes, à hidropsia e que era freqüente entre os escravos. Cinqüenta anos depois, Labat a descreve em Guadalupe, enquanto que no curso dos séculos XVIII e XIX os médicos 
a diagnosticaram um pouco por toda parte nos países tropicais e em certas regiões temperadas da América, da Europa e norte da África, assim como na Ásia e nas ilhas do Pacífico.

A anemia ancilostomótica recebeu os nomes de clorose do Egito, anemia dos mineiros, caquexia africana, anemia intertropical, amarelão e opilação; estes dois últimos no Brasil.

Em 1838, Dubini encontrou o parasito nos intestinos de uma mulher falecida de pneumonia, que autopsiara em Milão ${ }^{6}$. A ele deve-se a primeira descrição detalhada do verme e o nome Ancylostoma duodenale. Tendo encontrado o parasito várias vezes nas autópsias, foi levado a fazer pesquisas sistemáticas; mas, ainda que os exames se mostrassem positivos em $20 \%$ dos casos, ele não chegou a estabelecer sua relação com a anemia, visto que a causa mortis era geralmente outra ${ }^{17}$.

Coube a Griessinger (1851) e a Bilharz (1853), no Egito, o mérito de associar a presença e a ação dos ancilóstomas à clorose do Egito. Wucherer (1886) e outros médicos, no Brasil, confirmaram os trabalhos de Bilharz ${ }^{6}$.

A partir de 1878, o diagnóstico de ancilostomíase tornou-se fácil e preciso, graças aos trabalhos de Grassi e dos irmãos Parona, na Itália, que mostraram a possibilidade de estabelecê-lo buscando os ovos do parasito nas fezes dos pacientes ${ }^{6}$.

\section{EPIDEMIAS NA EUROPA}

Pouco depois (1880), uma epidemia de ancilostomíase devia declarar-se entre os trabalhadores italianos encarregados de abrir, nos Alpes, o túnel de São Gotardo ${ }^{18}$. Nessa ocasião, Perroncito teve que sustentar longos debates com seus colegas médicos que não aceitavam a etiologia parasitária da anemia.

Essas discussões não podiam senão estimular pesquisas que, finalmente, contribuíram para a introdução de dois medicamentos para tratar a ancilostomíase: o extrato de feto-macho e o timol. Este último passou a ser o medicamento de escolha até que, em 1917, foi adotado o óleo de quenopódio seguido, em 1922, pelo tetracloreto de carbono e, depois, pelo tetracloroetileno, descoberto em 1925. O tetracloroetileno foi extensamente utilizado em campanhas de massa, até que surgiram os antihelmínticos modernos, de largo espectro.

\section{O CICLO PARASITÁRIO}

Pouco antes do fim do século XIX, um acidente de laboratório deveria concorrer para esclarecer uma das questões de importância capital para o conhecimento do ciclo evolutivo e do mecanismo de transmissão da doença. Looss, trabalhando no Cairo, havia derramado acidentalmente sobre sua mão uma suspensão de larvas de ancilóstoma. Ao secar, o líquido produziu forte prurido e uma dermatite no lugar de contato. Pouco tempo depois, ele pôde verificar, pelo exame das fezes, aquilo de que suspeitava fortemente: tinha-se infectado por via cutânea.

Essa observação foi confirmada experimentalmente e conduziu-o a descobrir o ciclo completo do parasito ${ }^{618}$.

Sabia-se, então, que os ovos eliminados com as matérias fecais (e contendo apenas 4 a 8 células) formavam em 18 a 24 horas, se as condições do meio externo fossem favoráveis, larvas ditas rabditóides que abandonavam sua casca para se deslocarem na película líquida que envolve as partículas do solo, nutrem-se aí de bactérias e matérias orgânicas, até se transformarem em larvas de $2^{\circ}$ e de $3^{\circ}$ estádio, ao fim de 5 a 7 dias.

As larvas de $3^{\circ}$ estádio são as únicas infectantes para o homem. Elas já não se alimentam mais, mas permanecem ativas na superfície do solo durante semanas ou meses (até que se esgotem suas reservas nutritivas). A penetração se faz principalmente pela pele das extremidades inferiores. Através da circulação sangüínea, elas chegam aos capilares pulmonares, atravessam a parede alveolar, sobem com as secreções mucosas da árvore brônquica até a laringe e a faringe e, deglutidas, vão ter ao intestino, onde ocorrem as últimas ecdises e transformação final em vermes adultos, machos e fêmeas.

O ciclo mostra que o controle da ancilostomíase pode ser feito pela interrupção da transmissão em diferentes níveis ${ }^{14}$ :

1) tratando os indivíduos parasitados, para reduzir ou suprimir as fontes de infecção;

2) assegurando um destino adequado às fezes humanas, para impedir a contaminação da superfície do solo com os ovos e larvas dos parasitos (uso de fossas sanitárias e latrinas ligadas a um sistema de esgoto);

3) protegendo as pessoas contra a penetração das larvas infectantes, mediante o uso de calçado.

Após a epidemia de São Gotardo, a ancilostomíase tornou-se um problema grave na maioria das minas européias, aparentemente devido às migrações da mão de obra e às precárias condições de trabalho no fundo das galerias. Entretanto, a aplicação sistemática das normas estabelecidas para o controle da parasitose acompanhouse de notável sucesso em todos os países da Europa que as puseram em prática ${ }^{8}$.

\section{AS PRIMEIRAS CAMPANHAS DE MASSA}

Nos Estados Unidos, Charles W. Stiles, um zoólogo que, tendo completado seus estudos na Europa, havia aprendido muito sobre a ancilostomíase, demonstrou em 1902 que o agente causal da doença na América era um helminto diferente, que denominou Necator americanus $^{6}$. Ele devia reconhecer mais tarde que essa 
espécie é originária da África e que sua presença no Novo Mundo era conseqüência do tráfico de escravos.

Fazendo inquéritos nos estados do sul daquele país, Stiles constatou a importância dessa parasitose nas zonas rurais e, durante vários anos, insistiu sobre a necessidade de uma campanha de recuperação dos poor-whites que, nessa época, se acreditava serem preguiçosos, não doentes.

Seus apelos foram finalmente ouvidos e, em 1910, a Comissão Sanitária Rockefeller (que viria a tornar-se a Fundação Rockefeller) estruturou-se para pôr em marcha seu velho projeto, que, sob a direção de Wickliffe Rose, lançou-se ao trabalho ${ }^{18}$.

Durante 5 anos e com um orçamento total de quase um milhão de dólares, ele examinou em 11 estados do sul 1.300.000 pessoas e tratou 700.000.

O projeto falava de erradicação, mas Rose compreendeu logo seu equívoco. Stiles havia estimado em dois milhões o número de casos de ancilostomíase no sul, mas havia três ou quatro milhões.

Rose não acreditava que a Comissão, sozinha, pudesse ou devesse chegar à erradicação; mas supunha que o exemplo e a propaganda acabariam por mobilizar todos os médicos, todas as autoridades concernentes, assim como a população em geral para um esforço que levaria à erradicação.

Suas decepções começaram com a fraca colaboração do corpo médico; sobre 20.000 médicos rurais dos nove estados sulinos, de que ele esperava colaboração, poucos responderam ao apelo. Muitos perguntavam quem iria pagar o tratamento dos indigentes; outros, mesmo pagos, não fizeram muita coisa. No fim da campanha, devia-se constatar que apenas $30 \%$ dos médicos haviam aplicado tratamentos anti-helmínticos.

Sob a pressão de Stiles, Rose teve que aceitar uma solução que não lhe agradava: organizar ambulatórios gratuitos em cada localidade, onde, uma vez por semana, um médico da equipe vinha para as consultas e os tratamentos.

Diante das dificuldades que se apresentavam ao longo da campanha, a Comissão ensaiou fazer um esforço de erradicação total em uma vila de pescadores de menos de 600 habitantes, isolada na Ilha de Knotts, na Carolina do Norte. Mesmo nessas condições, a erradicação fracassou.

Ainda antes dessa experiência piloto, em 1913, havia sido criada uma Comissão Internacional, denominada mais tarde International Health Division, para repetir em outros países a demonstração gigantesca que se desenvolvia no sul dos EUA. Em 1921, os trabalhos eram feitos em mais de 30 países ou territórios, sobretudo na América Central, nas Antilhas, na Colômbia, no Brasil, no Egito, nas Índias e em outras regiões da Ásia e do Pacífico. Ao todo, quase 4 milhões de pessoas foram examinadas e 2 milhões de tratamentos foram aplicados ${ }^{18}$.

\section{OS RESULTADOS E SUA INTERPRETAÇÃO}

No Mississippi, onde se havia trabalhado intensamente e onde a educação sanitária havia sido beneficiada pelo apoio e colaboração da imprensa e dos meios escolares, um primeiro inquérito para avaliar os resultados, feito em 1933, mostrou que a prevalência baixara de $53 \%$ para $19,6 \%$ e, posto que apenas uma casa rural sobre dez possuía uma latrina satisfatória, a redução não era atribuível ao saneamento.

Entre os obstáculos ao controle da ancilostomíase, falou-se muito da não-cooperação de uma parte da população, ou seja da dificuldade de fazer com que as pessoas modificassem seus hábitos ou que aceitassem as latrinas rurais de construção econômica. Em verdade, os aspectos econômicos e sociológicos do problema haviam sido subestimados, quando eles são de extrema importância no controle de certas endemias.

Mesmo as condições de ordem epidemiológica não haviam sido tomadas em consideração adequadamente, pois:

- não se consegue descobrir todos os casos ou tratar todos aqueles que foram diagnosticados;

- os medicamentos não curavam todos os casos tratados;

- a contaminação fecal do solo, que havia sido causada pelas pessoas parasitadas antes da medicação, persiste ainda durante várias semanas ou alguns meses após o tratamento, se as condições locais do clima e do terreno permanecerem favoráveis à sobrevivência das larvas de ancilostomídeos;

- a poluição fecal do meio, pelos indivíduos não-tratados, não-curados ou reinfectados, continua a acrescentar novas quantidades de ovos do parasito no solo, que em determinados lugares do peridomicílio continuará fervilhando de larvas infectantes.

Nessas condições, a transmissão da ancilostomíase permanece ativa e assegura a reinfecção da população suscetível.

Em 1940, uma nova avaliação feita em oito estados sulinos dos EUA, mostrava que a taxa de positividade havia passado de $37 \%$ para $11 \%$ e que apenas um caso sobre dez apresentava sinais clínicos da ancilostomíase. A melhora ocorria sobretudo nos aspectos clínicos da infecção: as formas graves de anemia tornavam-se cada vez mais raras e, nos últimos anos, os médicos encontravam poucos casos de ancilostomíase-doença, apesar da presença da infecção nas planícies arenosas, desde as regiões costeiras do Mississippi até a Carolina do Norte.

Mas ninguém se iluda sobre as causas dos bons resultados alcançados nos EUA, a longo prazo. O desenvolvimento econômico havia modificado profundamente o quadro ecológico: a urbanização, a elevação do poder de compra da população rural, (com permitindo o uso cada vez mais generalizado e mais 
freqüente de calçados, a melhoria das casas instalações sanitárias adequadas), assim como da alimentação, são todos fatores decisivos da mudança e sem relação com as campanhas anti-helmínticas.

\section{ANCILOSTOMÍASE NO TERCEIRO MUNDO}

Que se passou nos países em desenvolvimento?

Tomemos como exemplo o Brasil, onde a Comissão Rockefeller havia examinado 77.436 pessoas, entre 1916 e 1921 , e encontrado $77,4 \%$ de casos positivos para ancilostomídeos ${ }^{519}$.

Nessa época (1918), Monteiro Lobato descreve em Urupês o caboclo brasileiro como um anemiado crônico, simbolizado na figura de Jeca Tatu, que, dizia ele, não é um preguiçoso, mas um doente.

Trinta anos mais tarde (1947-1952), os inquéritos parasitológicos do Ministério da Educação e Saúde, dirigidos por Amilcar Barca Pellon e Isnard Teixeira ${ }^{1213}$, que incidiram sobre 400.000 escolares do Nordeste e Centro-Leste do país, encontraram $46,1 \%$ de resultados positivos. Mais tarde, em 1969, os exames feitos pela rede de laboratórios do Ministério da Saúde (DNERu) ${ }^{20}$, sobre todo o território nacional, não encontraram mais que $28,8 \%$ de parasitados, entre os 2,5 milhões de exames feitos.

Essas porcentagens que, aparentemente, indicam uma evolução muito favorável, escondem no entanto a verdade. Os números prováveis de casos de ancilostomíase foram calculados pelos autores respectivos ${ }^{5121320}$, como mostra a Tabela 1.

Tabela 1 - Resultados dos inquéritos sobre ancilostomíase feitos no Brasil em diferentes épocas.

\begin{tabular}{lcc}
\hline Autor e ano & $\begin{array}{c}\text { Exames positivos } \\
(\%)\end{array}$ & $\begin{array}{c}\text { Estimativa do } \\
\text { número de casos }\end{array}$ \\
\hline Hackett, $1920^{5}$ & 77,4 & 23.500 .000 \\
Pellon e Teixeira, $1950^{12}$ & 42,5 & 22.300 .000 \\
Vinha, $1968^{20}$ & 28,8 & 24.000 .000 \\
\hline
\end{tabular}

A população parasitada permaneceu praticamente constante porque o número de pessoas expostas ao risco de infecção, isto é, a população rural, pouco aumentou nos últimos oitenta anos, enquanto que as condições ecológicas permaneceram quase sempre as mesmas. O enorme crescimento da população brasileira tendo sido sobretudo urbano, uma proporção sempre maior de pessoas escapa desse risco ${ }^{14}$, ainda que, ultimamente, os movimentos migratórios do campo para a cidade, em busca de trabalho, estejam criando nos bairros periféricos condições higiênicas tão precárias quanto as rurais.

Mas, nas regiões do mundo onde a explosão demográfica não foi acompanhada de um processo de urbanização rápido, deve-se esperar um aumento do número de pessoas parasitadas.

Em 1957, sobre 656.700 casos de ancilostomíase diagnosticados em 169 países ou territórios das regiões tropicais, mais de $2 / 3$ encontravam-se na África. Nesse mesmo estudo feito pela Divisão de Ciências Médicas da National Academy of Sciences, National Research Council (EUA), a ancilostomíase apresentava-se, dentre as doenças parasitárias, como a segunda causa de morbidade, depois da malária, e como a terceira causa de mortalidade, depois da malária e da amebíase.

Estimou-se no passado que os ancilostomídeos parasitavam um quarto da população mundial e esse cálculo pareceu muito razoável, ao menos para os 2 bilhões que, em 1975, formavam a população rural dos países menos desenvolvidos. Se considerarmos que muitas cidades pequenas do Terceiro Mundo também ofereciam um meio favorável à transmissão da parasitose, o número total de pessoas infectadas podia ser estimado, sem risco de exagerar, entre 500 e 700 milhões.

Ora, apesar da forte tendência à urbanização, a população rural desses países deve estar aumentando de 864 milhões, entre 1975 e 2000; e, como o saneamento e o nível econômico não se desenvolvem mais rápido que suas populações, a ancilostomíase tende a aumentar sua freqüência (como se verá adiante).

Então, que fazer?

Vejamos primeiro quais são os conhecimentos e os recursos atuais com que podemos contar para um esforço de controle eficiente da endemia.

\section{OS ANCILOSTOMÍDEOS E A DOENÇA}

As migrações humanas apagaram quase completamente os antigos limites de distribuição geográfica das duas espécies de helmintos que parasitam o homem: Ancylostoma duodenale (primitivamente na Ásia e Região do Mediterrâneo) e Necator americanus (originariamente na África subsaariana). Se, nas Américas, o A. duodenale chegou antes da descoberta, com as migrações humanas vindas através do Pacífico ${ }^{2}, 0 N$. americanus foi introduzido com o tráfico de escravos ${ }^{18}$. Esta última espécie vai se tornando cada vez mais prevalente nas diversas regiões endêmicas. 
Os conhecimentos sobre as vias de penetração e de migração larvária desses parasitos são mais precisos. Enquanto para o $N$. americanus a penetração cutânea é a única possível, para infectar uma pessoa, o A. duodenale pode penetrar também por via oral (com o consumo de legumes frescos, p. ex.) e, neste caso, deixar de fazer o ciclo pulmonar, completando todo seu desenvolvimento larvário nos intestinos do paciente, com maior proporção de larvas chegando à fase adulta.

Algumas observações, feitas sobretudo na Índia (Bengala Ocidental), sugerem que A. duodenale pode deter seu desenvolvimento, depois da infecção e só completálo tempos depois, coincidindo com o regime das monções, estação das chuvas, favorável para a propagação da infecção ${ }^{17}$.

As pesquisas sobre mecanismos patogênicos, utilizando rádio-isótopos para marcar as hemácias, permitiram seguir o destino destas no organismo ${ }^{131516}$. Assim, foi possível medir precisamente as perdas sangüíneas causadas pelos vermes, segundo a espécie e o número de helmintos albergados. Tornou-se mais clara a relação entre a espoliação sangüínea e a absorção de ferro, na produção da anemia, com o que pôde-se compreender a razão de existirem na mesma área endêmica casos de parasitismo sem anemia e casos de anemia sem parasitismo; ou porque a anemia pode ser desencadeada por cargas parasitárias tão diferentes (medidas pelo número de ovos por grama de fezes), segundo os países, os regimes alimentares ou as condições individuais.

Destacou-se, então, de maneira geral, a relação entre a intensidade do parasitismo e o volume de sangue perdido por dia: cerca de 2 a $3 \mathrm{ml}$ de sangue para cada 100 ovos/ grama de fezes, entre os camponeses da Venezuela infectados pelo Necator americanus ${ }^{15}{ }^{16}$.

Uma pessoa albergando 700 necátores, por exemplo, perde $22 \mathrm{ml}$ de sangue por dia, ou $11 \mathrm{mg}$ de ferro, dos quais $40 \%$ são reabsorvidos pelo intestino. A perda efetiva será portanto de 6,6mg e, se sua alimentação não lhe assegurar mais que uma reposição de 2,6mg por dia, o déficit cotidiano será de $4 \mathrm{mg}$. Ora, um homem de 60 quilos dispõe de quase $3.000 \mathrm{mg}$ de ferro total, dos quais $2.000 \mathrm{mg}$ ligados à hemoglobina e $900 \mathrm{mg}$ de reserva. Enquanto as reservas não se esgotarem, a hematopoese faz-se normalmente. Depois, a taxa de hemoglobina começa a baixar, mas, na nossa hipótese, serão necessários 220 dias para que isso aconteça.

Mas, à medida que o paciente vai ficando anemiado e se o volume de sangue retirado pelos parasitos permanecer constante, suas perdas de ferro diminuem, até que a quantidade de ferro perdida por dia se torne igual à fornecida pela alimentação do doente. Nesse momento a anemia se estabiliza. O nível de estabilização é função, evidentemente, da carga parasitária e da ingestão e absorção do ferro alimentar.

Desde que se administre ferro aos pacientes, a anemia melhora rapidamente, pois a capacidade de absorção intestinal e de utilização do ferro em circulação encontramse aumentadas nesses pacientes anêmicos. Se nós os tratarmos simplesmente com um anti-helmíntico, a recuperação será mais lenta, devido ao baixo teor de ferro na alimentação das populações das áreas endêmicas. Note-se, ainda que o ferro de origem vegetal, o mais abundante no regime dessas pessoas, é de absorção mais difícil que o de origem animal.

Nessas regiões de subnutrição crônica, a anemia persiste, por vezes, mesmo depois da desparasitação ou existe sem infecção ancilostomótica.

A anemia devida aos ancilostomídeos é de tipo ferroprivo, não havendo fator hemolítico envolvido ${ }^{11} 1516$. Se a vida média das hemácias é menor que a normal, isso se deve a um defeito de formação dos glóbulos vermelhos, ligado a um déficit protéico e à destruição precoce das hemácias pelo baço.

A hipoproteinemia é outro sinal clínico da doença, causando edemas e, em alguns casos, atrofia da mucosa intestinal, com redução e achatamento das vilosidades e diminuição da capacidade de absorção intestinal. Essa hipoproteinemia parece resultar das perdas intestinais, da ingestão insuficiente de proteínas na dieta (a anorexia podendo contribuir para isso), e da capacidade reduzida de síntese protéica pelo fígado, afetado pela anóxia resultante da anemia.

O caráter crônico, a evolução lenta e progressiva da doença, assim como a ausência de dramaticidade, na grande maioria dos casos de intensidade média ou leve, contribuem para um estado permanente de má saúde que tanto pode comprometer o desenvolvimento físico, mental ou cultural dos jovens, como a capacidade de trabalho dos adultos. Esse estado de saúde precária, predispõe os pacientes a sofrerem a ação de outros agentespatogênicos, eventualmente mais graves.

\section{IMUNIDADE E VACINAÇÃO}

As maiores lacunas no conhecimento sobre a ancilostomíase humana estão no setor imunológico. Não se tem, sequer, provas de que a infecção seja capaz de induzir o hospedeiro a produzir anticorpos protetores.

Suspeita-se que deva existir alguma proteção, ainda que fraca, porque a carga parasitária aumenta até a idade de 15-20 anos e se estabiliza depois, a menos que isso se deva a mudanças comportamentais dos pacientes, com redução do risco na idade adulta.
Na ancilostomíase experimental do cão, se o número de larvas empregadas na infecção inicial for suficiente, a reação imunológica resultante confere certa proteção contra uma segunda invasão, o que permitiu a utilização de larvas irradiadas para vacinar animais muito jovens ${ }^{7}$.

As maiores dificuldades de investigação, no caso humano, decorrem de não existirem modelos experimentais para a infecção por N. americanus ou por A. duodenale. 
Os riscos de usar material radioativo e o fato de que o homem se reinfecta muito facilmente ${ }^{4}$, em condições naturais, são de tal ordem que desencorajam as pesquisas em domínio tão problemático.

\section{PREVENÇÃO E TRATAMENTO NA ATUALIDADE}

Os recursos hoje disponíveis são vários ${ }^{914}$. O uso constante de calçado é condição básica para a prevenção das infecções e reinfecções e, portanto, para o êxito de quaisquer tratamentos; pois estes se tornam precários se ocorrerem reinfecções.

Conta-se atualmente com ampla gama de medicamentos eficientes e adequados para 0 tratamento da ancilostomíase, que proporcionam taxas de cura em geral acima de $85 \%$. Alguns são mais específicos, enquanto outros possuem largo espectro de ação, sendo portanto recomendáveis nos casos de poliparasitismo. Para o tratamento individual ou de massa, os mais recomendados ${ }^{11}$ são:

Mebendazol. Eficaz contra Necator, Ancylostoma, Ascaris, Trichuris e Enterobius, atuando sobre os vermes adultos e ovos por inibir a utilização da glicólise. Uso oral, administrando-se para adultos ou crianças $100 \mathrm{mg}$ da droga cada 12 horas, durante 3 dias. Para tratamento de massa em dose única, administrar $500 \mathrm{mg}$, em qualquer idade acima de 2 anos. Contra-indicado na gravidez.

Albendazol. Eficaz contra as duas espécies de ancilostomídeos e outros nematóides (menos ativo contra Trichuris e Strongyloides). Dose única de $400 \mathrm{mg}$, em qualquer idade acima de 2 anos. Atua sobre os vermes adultos, larvas e ovos. Contra-indicado na gravidez.

Pirantel. O pamoato ou emboato de pirantel induz paralisia espástica dos vermes adultos (Necator, Ancylostoma, Ascaris e Enterobius). Os ancilostomídeos requerem $10 \mathrm{mg} / \mathrm{kg} /$ dia durante 3 dias. Alguns autores recomendam $20 \mathrm{mg} / \mathrm{kg} / \mathrm{dia}$, em dose única

A anemia deve ser tratada com administração de ferro (p.ex.: sulfato ferroso, 200mg 3 vezes ao dia, durante 3 meses ou mais, e alimentação abundante, principalmente em proteínas e vitaminas.

Saneamento. A construção e o uso de latrinas ou de outros tipos de instalações sanitárias são aspectos importantes do saneamento ambiental, que devem ser avaliados quanto ao seu impacto a curto e longo prazo sobre o controle das parasitoses intestinais, relação custo/benefício, aceitação pelos moradores do campo, manutenção em condições satisfatórias, duração etc.

A educação sanitária deve visar mudanças comportamentais que reduzam a poluição fecal do solo, no peridomicílio e nos locais de trabalho, atuando junto a crianças e adultos.

\section{O PANORAMA ATUAL DA ANCILOSTOMÍASE}

O diagnóstico fácil e o tratamento eficaz dos casos fizeram com que, nas últimas décadas, esta doença perdesse muito de seu caráter dramático, na maioria das regiões endêmicas, o que tem levado em geral os governos e os serviços médicos à subestimarem sua importância em saúde pública ${ }^{1011} 21$.

No entanto, a Organização Mundial da Saúde ${ }^{22}$, em seu relatório de 1998, publicou as estimativas de prevalência para o ano de 1997, onde se vê que devem existir atualmente no mundo 1,25 bilhão de pessoas parasitadas por $A$. duodenale ou por $N$. americanus, das quais 151 milhões sofrem de ancilostomíase doença. A mortalidade causada por esta parasitose foi estimada em 65.000 óbitos, naquele ano.

Assim, a ancilostomíase, como entidade patológica específica, mata mais que outras, tais como raiva, meningite meningocócica, ascaríase, oncocercose, doença de Chagas, febre amarela, esquistossomíase ou cólera. Além disso, por seu caráter de padecimento crônico, contribui para a má qualidade de vida de um número considerável de pessoas.

Em 1994, no mundo em desenvolvimento, 2.284 bilhões de pessoas ainda viviam na zona rural em casas sem cobertura sanitária (OMS, $\left.1998^{22}\right)$.

\section{A ESTRATÉGIA NECESSÁRIA}

A experiência do passado e do presente sugerem que o controle da ancilostomíase deva levar em consideração o seguinte:

1. Será inevitavelmente um programa a longo prazo, buscando reduzir o número de pessoas parasitadas e a carga parasitária da população, mediante tratamentos anti-helmínticos periódicos e administração de sulfato ferroso, para os casos indicados.

Os resultados esperados compreendem a eliminação das formas clínicas graves da doença (anemia e suas complicações) e a redução da poluição fecal do meio com ovos de ancilostomídeos; e, conseqüentemente, a redução da transmissão da parasitose.
2. Para assegurar os meios e a continuidade desse programa, é indispensável que as decisões sejam tomadas nos escalões administrativos superiores do governo, inclusive naqueles responsáveis pelo financiamento.

3. Para assegurar a eficácia na aplicação das medidas propostas e sua continuidade no tempo, evitando também os problemas de comunicação e relacionamento com a população, é importante que a equipe de trabalho seja, ao menos em parte, recrutada localmente. Ela deve receber a formação adequada para compreender perfeitamente a natureza e a epidemiologia da doença, os objetivos, a estratégia e os métodos de ação, bem como tornar-se capaz de fazer trabalho educativo. Quanto 
maior for a participação de agentes da localidade, maior será a implantação regional do conhecimento necessário para o controle (válido igualmente para outros problemas de saúde).

A educação sanitária deve preceder e acompanhar todas as etapas do controle, mobilizando, motivando e organizando a participação da comunidade, com o objetivo de modificar seus hábitos higiênicos e de aceitar os tratamentos e as avaliações que forem necessárias. Ênfase especial deve ser dada ao uso de calçado, de forma constante, pelas pessoas de todas as idades.

4. Para que os bons resultados não sejam temporários, são necessárias medidas de saneamento (mesmo que venham a ser implantadas posteriormente às outras ações programadas).

A experiência tem demonstrado que os melhores resultados de programas dessa natureza, são obtidos quando há um desenvolvimento importante da economia regional, reduzindo a pobreza das famílias, melhorando as condições habitacionais, promovendo a alfabetização e a educação da população. O controle da ancilostomíase deve fazer parte de uma política de saúde abrangente, integrado numa política econômica nacional voltada para o bem estar de toda a população.

Essa é basicamente a orientação sugerida pela Organização Mundial da Saúde em suas últimas Assembléias Gerais $(1998,1999)^{10} 22$.

\section{REFERÊNCIAS BIBLIOGRÁFICAS}

1. Abdel-Razzah M. The use of radio-active isotopes to study some aspects of ancylostoma anemia. Transactions of the Royal Society of Tropical Medicine and Hygiene 50:318-325, 1965.

2. Araujo A. Origem dos ancilostomídeos parasitos do homem. In: Ferreira LF, Araujo A, Confolonieri U (eds) Paleoparasitologia no Brasil. PEC/ENSP, Rio de Janeiro, 1988.

3. Azevedo JF. A patogenicidade dos ancilostomídeos estudada pelos radioisótopos; 1 . A perda de sangue pelas fezes apreciada pelo ${ }^{51} \mathrm{Cr}$. Anais do Instituto de Medicina Tropical. Lisboa 222:1523, 1965.

4. Chandler A. The rate of loss and acquisition of hookworms. Journal of the American Medical Association 92:1337-1341, 1929.

5. Hackett L. Os cinco anos da Comissão Rockefeller no Brasil. Tribuna Médica, Rio de Janeiro 27:157-163, 1921.

6. Kean BH, Mott KE, Russel AJ (eds) Tropical medicine and parasitology. Classic investigations. 2 vols. Cornell Univ. Press, Ithaca and London, 1978.

7. Miller TA. Industrial development and field use of the canine hookworm vaccine. Advances in Parasitology 17:315-385, 1979.

8. Organiation Mondiale de la Santé. Bibliographie de l'ankylostomiase, 1920-1962. OMS, Genève, 1965.

9. Organiation Mondiale de la Santé. Infections intestinales à protozoaires et à helminthes: Rapport d'un Groupe Scientifique de l'OMS. Série de Rapports Techniques 666, 1982.

10. Organiation Mondiale de la Santé. Rapport sur la Santé dans le Monde 1999. Pour um réel changement. OMS, Genève, 1999.

11. Pawlowski ZA, Schad GA, Stott GJ. Infestation et anémie ankylostomiennes. Méthodologie de la lutte. Genève, OMS, 1993.
12. Pellon AB, Teixeira I. Distribuição da esquistossomose mansônica no Brasil Divisão de Organização Sanitária, Rio de Janeiro, 1950.

13. Pellon $A B$, Teixeira I. $O$ inquérito helmintológico escolar em cinco Estados das Regiões: Leste, Sul e Centro Oeste. Divisão de Organização Sanitária, Curitiba, 1953.

14. Rey L. Parasitologia. Ed. Guanabara, Rio de Janeiro, 1991.

15. Roche M. Anquilostomiasis y anemia. Boletín de la Oficina Sanitaria Panamericana 69:221, 1970.

16. Roche M, Layrisse M. The nature and causes of "hookworm anaemia". American Journal of Tropical Medicine and Hygiene 15:1029-1102, 1966.

17.Schad GA. Arrested development in human hookworm infections: an adaptation to a seasonally unfavorable external environment. Science 180:502-504, 1973.

18. Scott HH. A history of tropical medicine. 2 vol. Williams \& Wilkinsm, Baltimore, 1939.

19. Smillie WG. Sudies on hookworm infection in Brasil. Rockefeller Institute, New York, 1922.

20. Vinha C. Distribuição geográfica da ancilostomose no Brasil. Revista Brasileira de Malariologia e Doenças Tropicais 20:289318, 1968.

21. Vinha C. Necessidade de uma política sanitária nacional para combate às parasitoses intestinais. Revista da Sociedade Brasileira de Medicina Tropical 10:2997-3001, 1976.

22. World Health Organization. The World Health Report 1998; Life in the $21^{\text {st }}$ century. A vison for all. WHO, Geneva 1998. 